I Universidade Estadual de Campinas (Unicamp), Campinas, SP, Brasil

cortado.thomas@gmail.com

https://orcid.org/0000-0003-2243-8735

Thomas Jacques Cortado'

\title{
AOS POUCOS: AGENCIANDO PESSOAS, CASAS E RUAS NA PERIFERIA DO RIO DE JANEIRO
}

\author{
Ah, Deus do céu, nesse mundo só há Jesus, é muito brabo, \\ Thomas, é meio complicado a vida. A gente pra se viver o dia, Thomas, \\ a gente vive, mas é mesmo aquele negócio: trupica aqui, cai ali, \\ levanta ali, cai por lá e assim, e vai vivendo a vida! Vai vivendo a vida \\ (José, morador do Jardim Maravilha)
}

\section{CASA E MOBILIDADE: CONTRASTE OU CONTINUIDADE?}

À primeira vista, a casa representa o contrário da mobilidade. Sabemos que, no Brasil, a construção de casas serviu para territorializar minorias étnicas e classes populares, como no caso das aldeias missionárias, que queriam sedentarizar os índios nômades (Oliveira, I998), ou das vilas operárias, que tentavam "imobilizar a força de trabalho" (Lopes, I979). De modo geral, estudos em contextos coloniais e pós-coloniais (Mitchell, I99I) e pesquisas sobre moradia nos países capitalistas do centro (Rabinow, I995) ressaltaram o papel das casas no controle das populações. Do ponto de vista das práticas nativas, a oposição já não é tão clara assim. Casas são lugares de trânsito, por onde circulam muitas pessoas, parentes, visitas ou amigos. Nas regiões rurais do Brasil, Comerford (20I4: I I7) notou que as casas funcionam como "lugares de saída e chegada, de ausência ou presença, de idas e retornos cotidianos ou excepcionais". Investigações conduzidas nos mais diversos contextos socioculturais indicaram que as casas frequentemente estão articuladas a redes de circulação de pessoas que envolvem outras casas (Marcelin, I996), numa escala até transnacional (Handerson, 2012).

Esse, entretanto, é apenas um sentido da mobilidade - a mobilidade como deslocamento físico. Discutindo a circulação dos membros da diáspora libanesa, Hage (2005) sugeriu que nem todo deslocamento tem relevância na vida das pessoas. É preciso, argumenta o autor, perguntar por que um desloca- 
mento se torna um movimento significativo, um movimento existencial. Vejamos a diferença entre viajar (como turista) e migrar: ao contrário da primeira, que, em geral, se resume a colecionar prazeres e prestígios, a segunda forma de mobilidade envolve a busca por uma vida digna. Nesse caso, a pessoa está se deslocando para pôr sua existência em movimento, para caminhar rumo a uma vida melhor. E reciprocamente: uma vida viável pressupõe uma forma de mobilidade imaginária, o sentido de que se está "indo para algum lugar" (Hage, 2009: I07). Portanto, ao lado da mobilidade física existe uma mobilidade existencial. Esse desejo de mobilidade existencial, aliás, sobressai nos relatos dessas pessoas que, à semelhança dos moradores de Sarajevo hoje, se sentem paradas, no tempo e no espaço, aguardando a definição de um futuro melhor (Jansen, 20I4).

Qual seria então o significado da casa para a mobilidade existencial? "O projeto de melhoria de vida", sugeria Durham (I989) para os loteamentos periféricos de São Paulo, "parece se concretizar de modo muito marcante na casa própria". Observando moradores de uma favela do Rio de Janeiro, Cavalcanti (2007: I 26) chegou à mesma conclusão, apontando para "uma narrativa subjacente do progresso pessoal; uma narrativa atrelada a sua percepção de uma melhoria progressiva mas inegável de seu entorno". Essa imaginação do progresso encontrava nas transformações materiais da casa, que de barraco se tornara casa de alvenaria, sua principal evidência. De modo geral, onde prevalece a autoconstrução, a casa é "indicadora [indexive] e produtora de uma sensação de melhoria material, de um senso de agência" (Cavalcanti, 2007: 132).

Existe, por fim, um terceiro sentido da mobilidade: a mobilidade como variação afetiva, que eu proponho chamar de mobilidade intensiva, devido à inspiração deleuzo-guattariana dos estudos a seu respeito. Foram as pesquisas de Guedes (20I3a, 20I5, 20I7) sobre cidades nas fronteiras de expansão que atraíram minha atenção para esse tipo de mobilidade. Comentando o significado da categoria febre, usada para caracterizar momentos de intensificação da atividade econômica (causados pela mineração ou pela construção de barragens), resultando em aumento na circulação de pessoas, objetos e afetos, Guedes (20I3a: 43I) concluiu a "importância de se considerar a categoria de movimento não apenas como 'deslocamento', mas também como agitação, correria, frenesi, evocando aquelas paixões que a noção de febre parece captar tão bem". Aqui a casa se torna um lugar e um momento de resfriamento das paixões coletivas, de desaceleração da vida social, de estabilização das pessoas. "A casa, idealmente, remete à singular duração das coisas estáveis e sólidas, almejadas e mantidas a duros esforços diante das forças disruptivas do mundo". "Entrar em casa é sossegar, é deixar aquela agitação e correria lá fora" (Guedes, 20I7: 226 e 228).

Tendo como objeto o Jardim Maravilha, um loteamento na Zona Oeste do Rio de Janeiro, ${ }^{I}$ onde até hoje prevalecem autoconstrução e falta de infraestru- 
tura, o presente artigo visa a dois objetivos: em primeiro lugar, elucidar o lugar da casa do ponto de vista das três formas de mobilidade mencionadas, principalmente das duas últimas; em segundo lugar, estabelecer um quadro teórico para pensar juntamente essas três formas. Busquei inspiração no conceito de agenciamento, cunhado por Deleuze e Guattari, para estabelecer uma lógica do desejo, isto é, daquilo que movimenta os corpos. Força de atração e repulsão, o desejo liga e separa os corpos; não se resume a uma tendência espontânea do organismo ou a uma falta: ele agencia corpos heterogêneos, desprezando as fronteiras tradicionais entre o humano e o não humano. "O agenciamento é o cofuncionamento, é a 'simpatia', a simbiose". "A simpatia são corpos que se amam ou se odeiam, e a cada vez populações em jogo, nesses corpos ou sobre esses corpos" (Deleuze \& Parnet, I998: 65 e 66). Cabe lembrar que o conceito de agenciamento implica um duplo processo de territorialização e desterritorialização (Deleuze \& Parnet, I998: 87), isto é, de movimentação e apropriação do espaço vivido, e que os agenciamentos possuem duas faces: "Estados de coisas, estados de corpos (os corpos se penetram, se misturam, se transmitem afetos); mas também enunciados, regimes de enunciados" (Deleuze \& Parnet, I998: 85). A descrição do agenciamento, portanto, requer a compreensão dos discursos que ele produz e que o produzem.

Seguindo a perspectiva aberta por Deleuze e Guattari, podemos reformular a questão da mobilidade dentro de uma problemática mais geral: o que movimenta os corpos? As mobilidades físicas, existenciais e intensivas remetem, na verdade, às relações entre corpos, afetos e discursos, relações que possuem alguma coerência, embora essa não seja a de um organismo ou de um sistema. É preciso destacar aqui que o conceito de agenciamento ignora as fronteiras entre o humano e o não humano não porque lhes atribui igual agência, mas porque ambos intervêm na construção das relações entre corpos, afetos e discursos. Quando Deleuze e Guattari discutem as relações entre galhinhos [brins d'herbe] e pássaros, eles não estão apenas desenhando uma rede de actantes, dividindo a agência entre pássaros e galhinhos; o que lhes interessa é o papel desses galhinhos na sociabilidade dos pássaros, o fato de que assumem várias funções, como a de material para construção do ninho ou de meio de sedução durante as paradas nupciais. Assim, o galhinho "age como um componente de passagem entre o agenciamento territorial [nidificação] e o agenciamento de corte [sedução]" (Deleuze \& Guattari, I997: I I7). Por isso, nessa perspectiva, não basta afirmar que determinada entidade, humana ou não humana, age ou pode agir; é preciso explicitar a lógica que torna essa atuação efetiva, o sistema de atração e repulsão que faz essas entidades funcionarem em conjunto.

Nossa hipótese é a de que existe um agenciamento pessoa-casa-rua na periferia do Rio de Janeiro, um conjunto de discursos, afetos e movimentos que perpassa essas três entidades. Tal hipótese não é completamente nova. Durham (I989), em texto já mencionado, chamava atenção para uma orientação básica 
comum nas avaliações dos moradores da periferia sobre a cidade, o bairro e a casa: tanto a construção da casa quanto a urbanização do bairro só faziam sentido dentro "do projeto de melhoria de vida" dos moradores, apoiado "na crença no progresso". Ou seja, tanto a construção da casa quanto a urbanização do bairro contribuíam para o sentido de mobilidade existencial entre os moradores. Guedes (2017: 406), mais recentemente, sugeriu, do ponto de vista da mobilidade intensiva, um paralelismo entre pessoa, casa e cidade. Em particular, a tensão entre sossego e descontrole, central no discurso nativo, se repetia na percepção das três. "Se as febres são um período de descontrole, isto se aplica tanto à cidade quanto às pessoas": durante as febres, o descontrole se manifesta tanto nas despesas das pessoas, voltadas para a festa, quanto na forma da cidade, "movimentada e animada, com suas ruas abarrotadas, o dinheiro correndo, idas e vindas de gente de todo canto, confusão, malandragem, morte e festa se misturando" (Guedes, 20I5: I22). E, reciprocamente, "uma cidade ou uma casa sossegada - ou 'mais' sossegada, as gradações sendo decisivas - tendem a favorecer que uma pessoa, ela também, sossegue" (Guedes, 2017: 426). Enquanto Guedes recorre ao conceito de pessoa fractal para descrever esses paralelismos, acionando a chave da relacionalidade (Wagner, I99I), proponho falar de agenciamento: quando as pessoas falam em febres, estão designando uma força, concreta, que movimenta os corpos por meio de várias escalas diferentes.

Com base nas falas dos moradores, nas práticas de autoconstrução e nos modos como os moradores lidam cotidianamente com os problemas de infraestrutura, o artigo começa por analisar as relações entre pessoas, casas e ruas do ponto de vista da urbanização, insistindo em particular nas ramificações afetivas e semióticas da categoria progresso, usada pelos moradores para descrever a chegada das infraestruturas urbanas. ${ }^{2}$ Em seguida, examina as mesmas relações do ponto de vista da construção da casa, mostrando que elas impõem um ritmo peculiar à vida, congruente com a experiência da urbanização, antes de concluir sobre mobilidade e agenciamento.

\section{ANALÍTICA DO "PROGRESSO": CORPOS, AFETOS E DISCURSOS NA URBANIZAÇÃO}

\section{"Quando não tinha nada"... o "mundo circundante"}

O Jardim Maravilha é um típico caso de loteamento periférico (Maricato, I979; Santos, I980). Projetado pela companhia Obrasin, ele surgiu no início dos anos I950, na antiga zona rural do Rio de Janeiro. Inicialmente, não passava de um cartaz colocado no meio do matagal, à beira de uma estrada usada para escoar a produção agrícola local. Embora obrigada pela legislação municipal a realizar as obras de urbanização, a Obrasin já iniciara a venda dos terrenos mesmo faltando infraestrutura, tentando alcançar uma clientela de classe média, atraída pelos charmes bucólicos da região ou pela futura valorização dos terrenos. Essa clientela, entretanto, logo desistiu de comprar, devido à distância do Centro da 
cidade e à demora nas obras. Com efeito, muitos lotes permaneceram vazios durante anos, enquanto famílias pobres, oriundas do interior, ocupavam o resto dos terrenos, já que não tinham condições para comprar um perto do Centro, com acesso aos equipamentos urbanos. Esse quadro de imensas carências urbanísticas pouco se alterou até o final dos anos I970, quando a mobilização dos moradores levou à implantação das primeiras infraestruturas. A partir dos anos I980, a prefeitura, aos poucos, assumiu o papel de urbanizar o loteamento, construindo escolas e um posto de saúde. Essa ação culminou nos anos I $990 \mathrm{com}$ a inclusão do Jardim Maravilha no Programa de Urbanização de Assentamentos Populares (Proap), o que levou à urbanização da área então mais povoada do loteamento. Desde os anos 2000, a prefeitura vem levando essas obras para outras áreas dentro do loteamento, porém, até hoje, quase a metade dos domicílios ainda convive com esgoto a céu aberto, falta de asfalto e redes clandestinas de luz e água. Da aprovação do projeto de loteamento pela prefeitura em I95I à inclusão do Jardim Maravilha no Proap, foram mais de 45 anos; para quem mora nas áreas ainda não urbanizadas, são mais de 60 anos sofrendo com problemas de infraestrutura.

Por isso, quando perguntados a respeito do Jardim Maravilha na época de sua chegada, os moradores antigos do loteamento sempre têm a mesma resposta: "antes, não tinha nada". "Isso aqui, não tinha nada aqui. Aqui não tinha luz, aqui não tinha água, aqui não tinha nada, não tinha nada!” “Não tinha nada aqui, não tinha nada", me explicava dona Joaquina, uma imigrante portuguesa chegada no Jardim Maravilha já nos anos I950. "Mato e lama e valas negras. Não tinha nada, não tinha nada mesmo. Não tinha luz, não tinha água”. A despeito desse niilismo, esses relatos também apontam para conjuntos de práticas visando remediar essas faltas, com os moradores lançando mão de soluções engenhosas, aproveitando o que estava à disposição deles. Por exemplo, nos anos I950 e I960, os moradores puderam contar com a famosa "luz do bonde" - uma linha de bonde passava pela estrada que beira o loteamento. "Tinha uns postinhos aí com os fios que era a luz do bonde", me contava dona Joaquina, "mas não valia nada! Não podia ligar a geladeira, não podia ligar nada, era mesma coisa que não ter". O marido dela tinha feito um gato de luz com os postes do bonde, "puxando" a luz diretamente da rede que alimentava a linha de bonde até a "casinha" deles. A luz do bonde é um dos exemplos mais antigos, no Jardim Maravilha, daquilo que chamo de bricolagem infraestrutural: a construção de infraes trutura pelo aproveitamento não planejado da já existente ou pelo uso de materiais que não tinham esse destino. A bricolagem infraestrutural lembra o conceito lévi-straussiano de bricolage, segundo o qual o bricoleur não subordina os meios ao projeto, prevalecendo-se do que está à disposição dele - os moyens du bord (Lévi-Strauss, I960).3 "Puxava lá e um puxando pra outro, um puxava ali, daqui pouquinho vinha um outro emendava, puxava ali”, resumia Jair, que nasceu no Jardim Maravilha nos anos I960. Essa fala ilustra um mecanismo funda- 


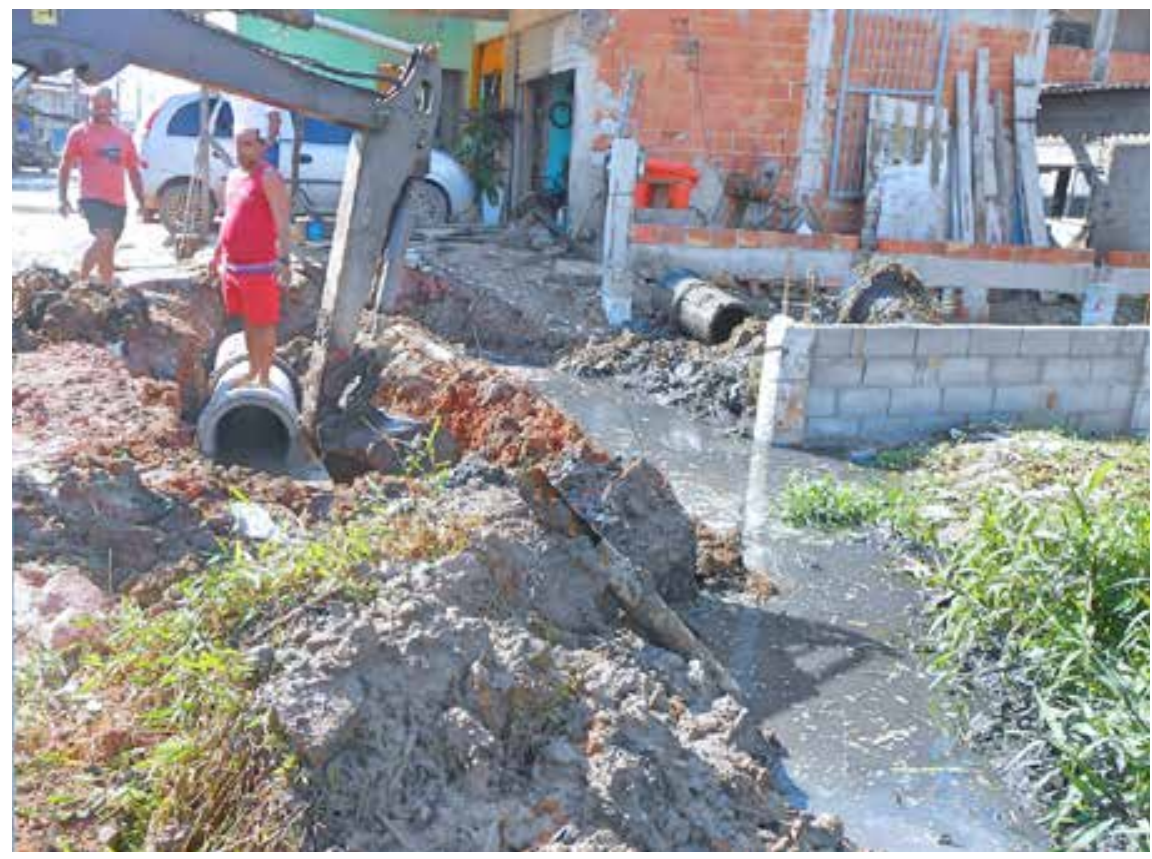

Figura I

Exemplo de bricolagem infraestrutural: colocação pelos moradores de um cano de esgoto em substituição à vala negra Foto do autor

mental da bricolagem infraestrutural: a produção de infraestrutura ocorre dentro de uma temporalidade descontínua, seguindo um princípio de contiguidade espacial, princípio resumido admiravelmente pelo verbo puxar. Essa mesma lógica do puxado prevalece hoje nas áreas ainda carentes de acesso regular(izado) à água encanada, com as pessoas puxando (colocando) canos das tubulações que ficam nas áreas urbanizadas para levar a água até suas casas.

Vale ressaltar que a bricolagem infraestrutural sempre ocorre no entorno das casas, prolongando o próprio cuidado dos moradores com elas. Se dona Fátima juntava os vizinhos para "fazer a rua", isto é, para aterrá-la, ela procurava seus vizinhos mais próximos, que moravam no mesmo "pedaço", e não todos os moradores da rua ou da quadra. De modo geral, a expressão minha rua, na boca dos moradores, não significa toda a extensão da rua em que moram, mas apenas o trecho ao redor de suas casas. Isso permite uma primeira caracterização do agenciamento pessoa-casa-rua: prevalece tanto nos discursos dos moradores quanto nas suas práticas o critério da disponibilidade, a presença de coisas úteis e manipuláveis, o que lembra o conceito de Zuhandenheit (manualidade) em Heidegger (2005). De fato, esse agenciamento muito se parece com aquilo que o fenomenólogo alemão descreveu sob o conceito de Umwelt (mundo circundante4), "que não é um mundo de objetos oferecidos à consideração teórica, mas um mundo de ferramentas disponíveis para a preocupação" (Vaysse, 2007: 4I).

Em outras palavras, o que Heidegger (2005: I08) chama de mundo circundante remete a entidades com as quais estamos familiarizadas, que fazem 
sentido na execução das nossas tarefas cotidianas (Heidegger, 2005: I08 e s.). ${ }^{5}$ E, de fato, predomina nas descrições dos moradores antigos a percepção de um mundo inospitaleiro, de um mundo que pouco oferece para o cumprimento dessas tarefas, conforme sugere a sua insistência nos três elementos mato, lama e brejo. Esses elementos pressupõem um espaço desabitado (pelo humano), sendo frequentemente associados, no discurso de moradores mais antigos, às poucas casas que existiam dentro do loteamento. "As casa eram muito sorteada, e os lotes aqui era tudo não construído", comentava Nelson, nascido no Jardim Maravilha nos anos I96o. "Era tudo mato! Muito mato, muita lavoura". O mato, a lama e o brejo também remetem a presença de "bichos", de animais que não são domésticos ou de criação. "Então era muito mato, muito, cara, tu tinha cobra jiboia", explicava Nelson. "Era diversas cobra. Sapo. Muita rã. Então os bicho invadia a casa quando a enchente vinha". O mato, a lama e o brejo descrevem assim um mundo que serve de esconderijo para uma flora e uma fauna hostis, estranhas à presença humana. ${ }^{6}$

O caso da lama merece destaque especial, posto que funciona como um "conversor de agenciamento" (Deleuze \& Guattari, I997: I I7). Por um lado, a lama chama atenção por dificultar os deslocamentos do cotidiano. As pessoas são obrigadas a inúmeras contorções para evitar os buracos na rua, correndo o risco de escorregar e quebrar uma perna, o que preocupa muito os moradores idosos ou que têm parentes idosos. Para ir ao trabalho, é preciso colocar sacolas de plástico nos pés para não sujar a roupa. Já os carros podem ficar com as rodas atoladas na lama, além de sujar a carroceira. O asfalto, nesse caso, representa a possibilidade de andar a pé ou de carro sem dificuldade e limpo. Por outro lado, a lama funciona como indício do abandono vivenciado pelos moradores das áreas ainda não (totalmente) urbanizadas. "Você quer lutar por um bem comum, pra melhoria de condições de pessoa poder sair de casa, sem pisar na lama", me contava Jair, cujo pai foi um fundador da antiga associação de moradores. "Às vezes tu tem teu carrinho, você chega, você se dará tudo cheio de lama, 'Qual é essa pô, tá tudo cheio de lama'. Aí a pessoa pensa, 'Essa é uma área descuidada'." "Pisar na lama" serve de metáfora para o sentimento de abandono: "eles no asfalto, e nós pisando na lama". A lama, nesse caso, integra um agenciamento que envolve a relação entre os moradores e o poder público.

\section{INTRODUZINDO A PERCEPÇÃO DO TEMPO NO "MUNDO CIRCUNDANTE": PROGRESSO E MOVIMENTO}

Se antes "não tinha nada", com a chegada das primeiras obras nos anos I970 e, sobretudo, graças ao Proap, o loteamento começou a "crescer", a conhecer o "progresso". "Isso aqui cresceu muito", contava dona Fátima. "Muita coisa né. Eu nunca imaginava, não sinceramente eu não imaginava que isso aqui fosse ficar assim, uma cidade! Praticamente uma cidade. É tudo loja, lojas e coisa de bolo, de supermercado, né." Criada num sítio ainda carente de infraestrutura 
que fica em Guaratiba, dona Ana, ao compará-lo com o Jardim Maravilha, onde mora desde os anos I980, enalteceu o progresso do loteamento. "Lá, não chegou o progresso não. Lá, continua mesma coisa. Progresso nenhum. Pra tu vir ônibus é longe, não entra uma condução [...]. Mas aqui o progresso, sem comparação. O Maravilha cresceu muito". O progresso se opõe então ao atraso. "Tava muito pouca casa!", exclamava dona Amélia, moradora antiga do Jardim Maravilha, também nascida em um sítio da região. "Não tinha padaria, não tinha mercado, não tinha nada disso que você tá vendo aí. Era um lugar muito atrasado, muito atrasado".

A experiência da urbanização, subsumida na categoria nativa de progresso, coloca o tempo no centro das relações entre pessoa, casa e rua. Chamam atenção os verbos usados pelos moradores quando falam a respeito da urbanização: evoluir, crescer, melhorar ou valorizar. São verbos dinâmicos (que expressam uma mudança), durativos (cuja ação se estende no tempo), mas também atélicos (desprovidos de uma finalidade intrínseca), graças à banalização das formas intransitivas, como na expressão o bairro melhorou ou valorizou. Assim, eles colocam a percepção do movimento (enquanto processo) no primeiro plano, uma percepção quase abstrata, já que os objetos concretos afetados pelo movimento (processo) tendem a desaparecer atrás do próprio movimento - "Isso aqui cresceu muito". Eles também sugerem um movimento (processo) ascendente, que vai se intensificando: a urbanização torna o mundo a cada vez mais hospitaleiro.

À percepção de um processo que vai se intensificando corresponde também a de uma expansão, de um maior movimento dentro do loteamento, como evidencia dona Joaquina:

Agora esse Maravilha, ele ficou muito parado. Quando eu vim pra aqui, como eu falei, tava tudo parado, não tinha nada, mas depois evoluiu de repente. [...] Começou a entrar a Prefeitura, fazendo esgoto. Depois mais tarde veio a luz, botaram água, quando fizeram o asfalto depois mais tarde. E foi... isso cresceu assim.

Os moradores em geral compartilham essa percepção de um lugar mais movimentado. Nesta perspectiva, o movimento é para o progresso o que o lugar parado é para o atraso. "Depois que começou a vir o movimento, começou a vir a Light”, contava Jair, cuja rua, embora sem asfalto, conta com iluminação pública e água encanada. À semelhança do progresso, o movimento se refere não só à urbanização do bairro como ao desenvolvimento do comércio, ao movimento das vendas e à diversificação das lojas - afinal, a presença de comércios ajuda a tornar o mundo mais habitável, disponibilizando novos objetos e novos serviços, para melhorar o cotidiano.7 O movimento designa também o aumento da população, o fato de o bairro "encher de casas", tal percepção de preenchimento contrapondo-se à distância que antigamente existia entre as casas.

À urbanização está atrelado mais um processo: a valorização. Algum lugar valoriza quando o valor dos imóveis sobe e novos usos do espaço apare- 
cem, permitidos pela instalação de equipamentos - ou seja, valorizar envolve o valor de troca, mas também de uso do solo. Esse duplo significado transparece na percepção que alguém como Paulo tem do Jardim Maravilha, tendo se mudado para lá pouco antes de a prefeitura abrir um túnel na serra vizinha, que facilitou grandemente os deslocamentos até o Centro da cidade.

Paulo: E essa abertura aqui, ficou muito valorizado. Até os terrenos...

Thomas: Tu percebeu?

Paulo: ... mudaram de preço. Eu percebi. Subiu, subiu muito! Mudou demais mesmo com a abertura, sendo que facilitou muito a deslocada da Barra pra cá. [...] Mas depois que abriu isso aqui, essa região aqui foi muito valorizada, muitas coisas aqui dentro a ser... não sei se chegou a observar, pode observar que aqui dentro, tem várias pessoas construindo, refazendo as casa, acrescentando, mais andar e tudo, construindo casas novas. Crescendo muito mesmo. [...] Mudou muito, até os valores, terrenos que eram de $30 \mathrm{mil}, 20 \mathrm{mil}$, mano quer 40, 60, 80. É que... as coisas mudou muito. Valorizou muito.

Portanto, a valorização está correlacionada ao movimento, com mais gente procurando e construindo casas. De novo, evidencia-se que a percepção do progresso deriva de um "olhar circunspecto" (Heidegger, 2005: I I I), de uma familiaridade prática com o "mundo circundante": não é nos dados estatísticos da prefeitura que eles se dão conta do progresso, mas nas transformações do mundo - o mato cedendo o lugar a novas casas, a lama trocada pelo asfalto, novos comércios surgindo na beira da avenida, novos prédios preenchendo os terrenos baldios.

Se o progresso temporaliza a experiência dos moradores, obrigando a distinguir entre o atraso e o evoluído, ele também impõe um ritmo específico à existência cotidiana. Por um lado, o progresso se manifesta de modo extraordinário, e muitas vezes espetacular, nas grandes obras de urbanização, como o Proap, ou na chegada de serviços que antes não existiam, introduzindo uma ruptura no tempo vivido pelos moradores, criando um divisor de águas a partir do qual eles constroem uma memória do lugar. Há sempre um antes e um depois do asfalto, um antes e depois das obras, que justifica, retrospectivamente, por que antes não tinha nada. Aliás, os moradores costumam comemorar a chegada das obras, como mostra Stella, cuja rua foi asfaltada no início dos anos 20 Io.

Tu não tava aqui, que eles não fizeram a calçada, botaram só asfalto na rua e a calçada eles deixaram no barro, ali da rua da minha mãe, o povo já tava superfeliz comemorando! Tinha festa na rua, os moleque descendo de skate, e passava moto pra cima, pra baixo, o povo não tava nem aí, o povo tava feliz de ter um asfalto ali, falava: "Agora posso subir com carro, agora vai ter festa na rua, Kombi vai passar aqui", era uma alegria absurda!

O progresso, nesse caso, compõe uma série disruptiva de eventos marcantes, porém espaçados. Por outro lado, o progresso transparece na série dos 
pequenos aperfeiçoamentos que mudam o cotidiano, "aos poucos", conforme indica o relato de Roberto, morador do Jardim Maravilha desde os anos I960.

\begin{abstract}
Aí botaram água, botaram água só num lado de rua. Depois fizeram o asfalto, não, eles botaram água dos dois lados. Tem água do lado de cá e água do lado de lá. Mas na época não botaram, era só de um lado. Você tinha que cortar o barro, fazer ligação até a água. Aí melhorou, melhorou muito! [...] A posteação entrou em 69 mais ou menos. 68, 69 já tinha posteação. Mais pra frente uns quatro anos, cinco botaram iluminaria pública, que nem era aquela, era o prato redondo, depois botaram essa de mercúrio. Foi evoluindo! E hoje, beleza!
\end{abstract}

É a duplicação dos troncos distribuidores que garante o abastecimento das casas com água potável; é a entrada de uma nova linha de ônibus para dentro do bairro; é a birosca que virou bar, oferecendo aos seus fregueses shows de música ao vivo e cervejas importadas. Até parece que o progresso segue os ritmos da vida cotidiana; ao lado das obras que introduzem uma ruptura na ordem da vida cotidiana, particularmente as obras de asfalto, tudo acontece "aos poucos" - "aí melhorou, foi melhorando aos pouquinhos, melhorando, melhorando", comentava Lúcio, usando dos mesmos termos que tinha aplicado ao crescimento demográfico do bairro, "foi chegando aos poucos! Chegando aos poucos, um faz um aqui, outro daqui uns tempo, faz um lá na frente, e aí foi povoando, povoando". "Na época, o que veio pra gente foi a luz, acho que eles conseguiram vir trazendo aos poucos. A luz e... trazendo a abertura das ruas. Que na verdade não era rua, bem rua, era caminhozinho entre os matos, entre o matagal", acreditava Carla, nascida no Jardim Maravilha nos anos I980, corroborando a fala da própria mãe: "Eu só lembro de que foi chegando a energia aos poucos, por distante, entendeu, e foi chegando pra cá, não sei como”.

Aos poucos... O que parece estar em jogo aqui, é a construção de uma memória específica a respeito do mundo circundante, da rua. A redução da intensidade atribuída ao progresso, que perde seu caráter disruptivo, está correlacionada a uma ampliação dos eventos aprendidos por meio dessa categoria: os mil pequenos aperfeiçoamentos da vida cotidiana. Ou seja, o que a categoria perde em intensidade, ela ganha em extensão, e, nesse ganho, é toda uma narrativa da vida cotidiana que se configura, uma narrativa que envolve pessoas, casas e ruas. As inúmeras materialidades que povoam o mundo da vida cotidiana passam a definir uma memória. O poste de luz, por exemplo, se torna parte de uma sequência que começa com a luz do bonde, e prossegue com os postes de madeira e as lâmpadas de baixa potência.

\title{
ANALÍTICA DA CASA AUTOCONSTRUÍDA: EVOLUIR E SOFRER Evolução da casa e da pessoa
}

A narrativa do progresso manifesta o olhar circunspecto dos moradores; palavras como crescer, evoluir e valorizar denotam uma avaliação pragmática do mundo circundante, a avaliação de alguém que lida com as tarefas concretas 
da vida cotidiana, próprias ao lugar onde mora. É a partir da casa que os moradores exercem esse olhar circunspecto sobre coisas e pessoas. É a partir dela que avaliam a disponibilidade das coisas e criam amizades; discriminam as distâncias (o próximo e o longínquo); transformam o espaço. Problemas como falta de água encanada, esgotos a céu aberto e ausência de iluminação pública fazem sentido a partir das casas; afinal, são as casas os lugares de onde partem e aonde chegam as infraestruturas urbanas, como uma multidão de nós para os quais convergiriam nossas imensas redes sociotécnicas, nossos cabos de luz e nossos canos de água. Acontece que uma narrativa semelhante à do progresso organiza a percepção que os moradores têm de suas casas. É que a casa "aumenta", "valoriza", sofre "reforma". Com isso, ela também se movimenta, se transforma, e a sincronia entre os dois movimentos, entre as transformações do bairro e da casa, confere sua relevância à narrativa do progresso.

Vale lembrar que as pessoas depositam nas suas casas suas esperanças em uma vida melhor: melhorar e evoluir não se aplicam apenas ao lugar, mas também às pessoas. Dona Elisabete passou parte da vida em uma favela do subúrbio carioca até se mudar para o Jardim Maravilha, no início do século, por causa da violência. Agora que a rua dela está asfaltada, ela reclama muito dos parentes que continuam morando lá: “Tem que evoluir na vida!". Evoluir significa sair da pobreza, mas também do atraso, dois traços que dona Elisabete atribui à favela. De modo geral, uma pessoa evolui porque, ao aumentar sua renda, adota um novo padrão de vida, se mudando de uma casa autoconstruída para um apartamento financiado, por exemplo - ou seja, uma pessoa evoluiu porque melhorou de vida. Ao contrário, não evolui quem continua com os mesmos gostos, as mesmas ideias, os mesmos projetos, como se nada tivesse mudado na sua vida. Assim, espera-se de uma pessoa, e de uma pessoa pobre em particular, que ela evolua, que ela busque melhorar de vida - a evolução funciona como um imperativo social, que retroage na percepção que se tem das pessoas.

A casa, principal bem das famílias pobres, apresenta-se como a maior evidência do quanto elas evoluíram. Quem melhorou de vida mora em uma casa "bonita". Em geral, tal casa comporta vários quartos: um para o marido e esposa, um para os meninos e outro para as meninas; vários banheiros, sendo um de uso social e outros anexados aos quartos, tipo suíte; paredes externas emboçadas, pintadas e/ou azulejadas; um segundo andar com varanda ou algum espaço para organizar festas. Já o mais pobre mora em um barracão, uma construção precária, feita de madeira. Entre os moradores antigos, muitos começaram por levantar um barracão, aproveitando a madeira e o barro da região. Em seguida, ou quando já têm tempo e recursos, constroem casinhas, imóveis de pequeno porte, principalmente cômodo e meia-água. Chama-se de cômodo uma pequena casa, geralmente quadrada, de um cômodo só, com banheiro fora. Nesse cômodo, as pessoas tanto comem quanto dormem e assistem à televisão, 
não havendo divisões internas. Já a meia-água consiste em uma pequena casa de telhado, com as seguintes divisões: quarto, cozinha, eventualmente sala, e banheiro (Cortado, 20I9). Tipicamente retangular, a meia-água costuma ocupar os fundos do terreno, no sentido da largura. A parede traseira da casa, nesse caso, serve de muro divisor com o terreno vizinho dos fundos, quando o morador não se apoia no muro já existente para construir sua meia-água, diminuindo os gastos com material de construção. Tanto o cômodo quanto a meia-água não precisam de estrutura, categoria nativa que designa os elementos de concreto (alicerce, colunas e laje). Ou seja, para construir um cômodo ou uma meia-água, basta assentar o tijolo diretamente no chão e colocar o telhado: são casas que não necessitam de muitos investimentos, cujas obras não demoram. Por isso também, o cômodo e a meia-água não oferecem perspectivas de ampliação, que são tantas possibilidades para as pessoas se projetarem em um futuro melhor.

De fato, a trajetória de muitos moradores no Jardim Maravilha consistiu em trocar progressivamente o cômodo ou a meia-água por uma casa com estrutura, capaz de suportar futuras expansões. Foi o caso de dona Ruth, que chegou ao Jardim Maravilha no início dos anos I990. Recém-divorciada e com uma filha, ela queria se mudar rápido. Comprou um lote na área ainda não urbanizada do loteamento e construiu um cômodo, com sala, quarto e cozinha no mesmo espaço, mais um banheiro anexado à parte traseira do imóvel. Aos poucos, com o dinheiro que ganhava trabalhando para uma firma de limpeza, a ajuda dos irmãos que já moravam no Jardim Maravilha e também o apoio dos diversos "paqueras" que tinha naquela época, ampliou o cômodo, acrescentando-lhe uma cozinha. O cômodo virou então uma meia-água.

A essa altura, a casinha ainda era de telhado. Após encontrar seu futuro marido, morador do Jardim Maravilha também, que veio morar com ela, dona Ruth substituiu o telhado por uma laje de concreto. Como a meia-água não possuía colunas, fez a estrutura, levantando-as no perímetro da meia-água. Porém, no dia de colocar a laje, que o sogro tinha dado de presente, ocorreu um acidente: ela desmoronou, destruindo o interior da casinha. Dona Ruth culpou a fraqueza do alicerce pelo acidente e decidiu refazê-lo. Concluído o novo alicerce, pediu demissão para, com o dinheiro da indenização, comprar outra laje. Pôs a nova laje em cima da meia-água e iniciou, no andar de cima, a construção da sala, do quarto, da cozinha e do banheiro. Quando o filho que teve com o novo marido já não era mais criança, ampliou esse andar, acrescentando mais um quarto e uma área de serviço. $O$ andar de baixo, da antiga meia-água, ficou desocupado, devido aos problemas de enchente que atormentam essa região do Jardim Maravilha.

Se, no caso de dona Ruth, a construção da casa não cumpriu um plano preestabelecido, acontecendo de acordo com a composição do grupo doméstico (chegada do marido e do segundo filho, que foi crescendo) e seu desejo de me- 
lhorar de vida, outros moradores tentam seguir um projeto. ${ }^{8} \mathrm{~A}$ realização desse projeto faz então com que os moradores percebam uma constante evolução. Para conceber o projeto da casa, os moradores podem recorrer a desenhos e papeizinhos, que eles guardam durante as obras, para orientar os pedreiros e lembrar-se de cada etapa. Alguns aproveitam sua experiência profissional, como marceneiro por exemplo, produzindo plantas mais detalhadas. De modo geral, os moradores que têm um projeto levantam uma meia-água na frente ou nos fundos do terreno, antes de construir a casa projetada no lugar desejado, para ter algum lugar onde morar. Uma vez o projeto concluído, a meia-água é demolida, incorporada ao edifício principal, transformada em oficina ou até alugada.

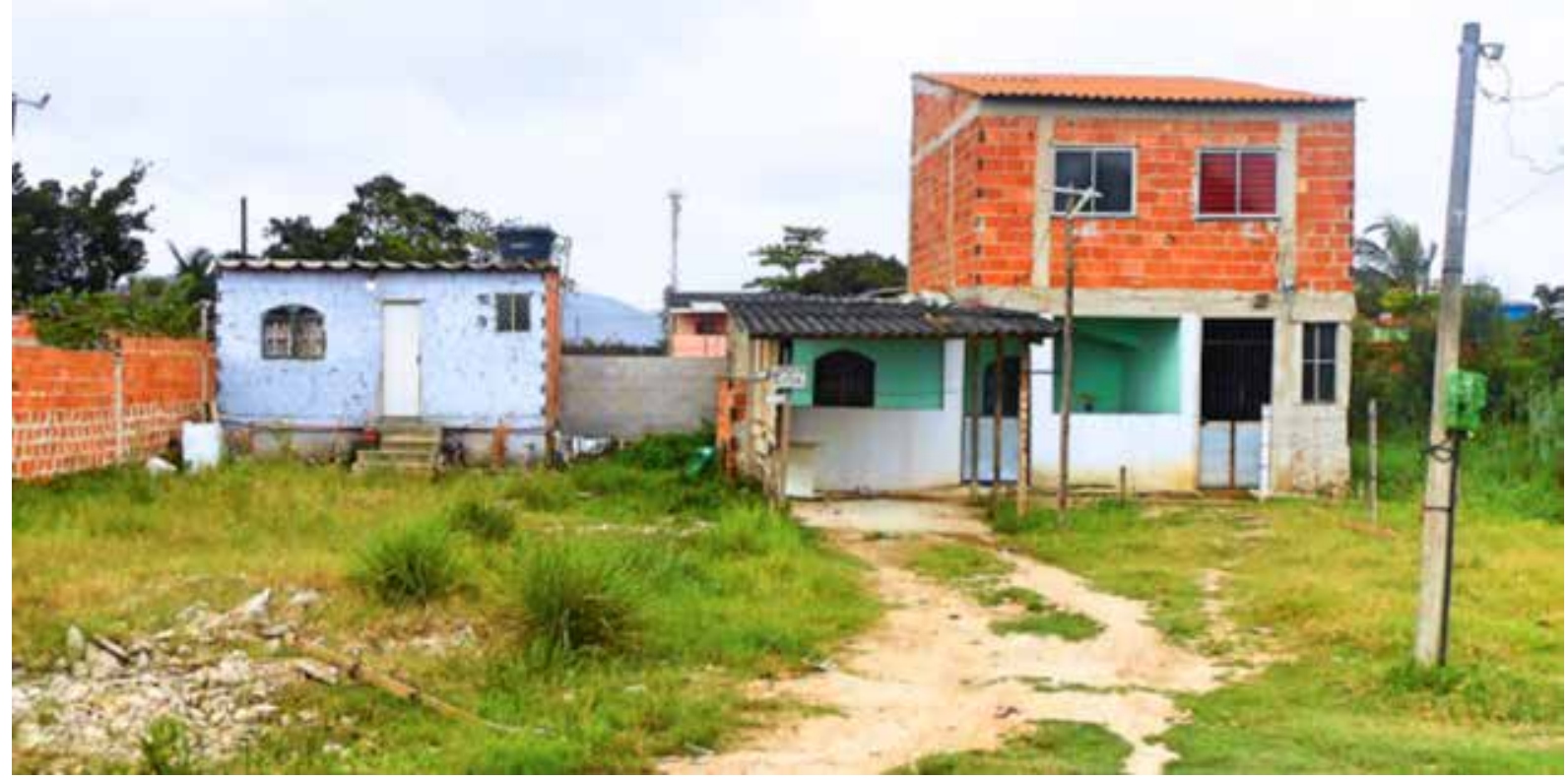

Figura 2

Duas meias-águas: à esquerda, na sua forma original, à direita, após sucessivas reformas e ampliações Foto do autor 
Ao trocar a madeira do barracão pelo tijolo, ao substituir o telhado caído da meia-água pela laje de concreto, ao se mudar dos fundos para a frente do terreno, ao transformar o cômodo em uma casa dividida, a pessoa evolui, experimenta uma transformação afetiva e semiótica. Aqui, como no caso da urbanização, estamos lidando com um movimento (processo) ascendente, que repercute na percepção do tempo: o desejo de uma vida melhor suscita uma narrativa voltada para o futuro, que abrange o amplo leque das materialidades domésticas, cujas alterações se tornam tantos episódios significativos. Isso fica mais aparente ainda quando a construção da casa decorre de um projeto: nesse caso, o próprio projeto é que serve de suporte à produção dessa narrativa. A contrapartida desse desejo por uma casa melhor está na existência de uma rigorosa hierarquia de estilos arquitetônicos, que a categoria de casinha evidencia: a casinha não é apenas uma casa pequena, uma casa menor, mas uma casa que ocupa um lugar inferior nessa hierarquia - a casinha é uma casa que a gente não consegue chamar totalmente de casa.

\section{AOS POUCOS, NO SOFRIMENTO}

À semelhança do progresso, a construção da casa também acontece aos poucos, seguindo um movimento lento e um ritmo de baixa intensidade.

Amélia. Fizemos uma casa, levou até a laje! E depois, fomo devagar né! Devagar, devagar, devagar, devagar... Emboçava, emboçamos dois cômodos, aí fez agora dois cômodos e depois fez mais emboço nos dois cômodos, aguardando dois cômodos, assim, aos pouquinho né.

Thomas: Foi aos pouquinhos?

Amélia: É, porque ele era motorista de ônibus né. Já tinha três filhos já na época. Aí foram nascendo. Aí já foram logo três. Aí não dava condição de pegar e trazer tudo de uma vez, não tinha condição. E fomos aos poucos. Aos poucos, aos poucos. Quando chegava assim, décimo terceiro, e férias, que ele tirava férias e em vez de tirar as férias ele ficava trabalhando, recebia aquelas féria e ainda recebia trabalhando! Aquele dinheiro ele dava tudo aqui. Se tinha que fazer um piso, comprava piso, se tivesse que pagar mão de obra, pagava mão de obra, e assim fomos fazendo.

"Obras" acontecem "aos poucos", repetia Carlinho, "igual formiguinha", "formiga que faz isso, vai botando uma areiazinha e aí já um formigueiro". Se é preciso fazer aos poucos, é porque nunca o dinheiro disponível basta para fazer a obra de uma vez. "Quando tinha um pouco de material que desse pra começar, chamava o homem e ele construía até gastar aquele material. Aí depois a gente tinha que ganhar mais dinheiro pra comprar outro (rindo). Era assim. Foi às etapas. Foi à etapa", explicava dona Joaquina. "Aí a gente levantou as paredes da outra parte, aí... esperou um pouco juntar dinheiro, aí bater a laje, aí juntar dinheiro de novo pra fazer o emboço", contava dona Eurídice. A própria dinâmica das obras obriga a fazer por etapa, já que "uma coisa puxa a outra", uma 
reforma chamando outra. "Vamos aos pouco, tem que ser aos pouco. Obra gasta né", dizia dona Clara. "Obra gasta, uma coisa puxa a outra, você compra piso, tem que comprar a massa. Se você não coloca, tem que pagar pra que alguém colocar, e uma coisa, você bota logo logo o piso, você tem que rejuntar o piso, e assim, então, tem que fazer tudo..."

Assim como a urbanização da rua, a construção da casa sempre coloca os moradores na posição de quem espera. É preciso esperar o dinheiro entrar, seja salário, aposentadoria, empréstimo, novo cartão de crédito, indenização (como no caso dos acordos com o patrão: dona Ruth pediu que fosse demitida para comprar uma nova laje), férias remuneradas, décimo terceiro etc. São muitas vezes entradas de dinheiro irregulares, como as indenizações, ou que ocorrem a cada ano, como as férias remuneradas e o décimo terceiro. Juntas, elas dão um ritmo peculiar à construção, formando a percepção de que tudo acontece... aos poucos.

Além do dinheiro, falta tempo. É preciso esperar determinados momentos durante o dia, a semana e o ano para trabalhar na obra. Bernard, que "pegava serviço" de noite, aproveitava a tarde para "avançar na obra"; Cláudio só tocava a obra nos fins de semana, comprando "um pouquinho de material", aquilo que dava para ele trabalhar "naquele fim de semana".

Entretanto, mesmo fazendo aos poucos, nem sempre os moradores conseguem levar a obra adiante. Dona Ana, por exemplo, chama sua casa de elefante branco, expressão aplicada a obras públicas sem utilidade ou que nunca acabam. Pouco antes de o marido morrer, dona Ana tinha construído uma casa atrás da casa de seus pais, nos fundos do terreno. Depois de o pai sofrer um derrame, convidou a mãe a trocar a casa da frente pela casa dos fundos, já que a da frente, maior e ainda em obra, precisava de mais cuidado. Dona Ana ficou então com a casa da frente. Quando o pai faleceu, a casa dos fundos ficou com a mãe até o final de sua vida, quando então a casa ficou com a irmã mais nova. Viúva e com três filhos para criar, entretanto, dona Ana não consegue "colocar dinheiro na obra", pelo menos não tanto quanto ela queria. "Minha mãe morreu, minha irmã ficou com a casa dos fundos, e eu fiquei com a casa, fiquei com o elefante branco porque até hoje eu tô tentando fazer a obra, não consigo", lamentava dona Ana. "A [casa] da frente que é o elefante branco porque... sabe como que tá a obra, cara pra caramba... vou fazendo o que eu posso (ênfase). Tô tentando fazer, mas a minha lá era tão bonitinha", me contou ela novamente, deixando transparecer certo arrependimento pela troca, certa saudade da casa que tinha. A imagem de um passado melhor, da "casa tão bonitinha", se contrapõe à imobilidade presente (o elefante branco). A obra parada, que não consegue avançar, também impede os moradores de avançar na vida.

Longo, demorado, o caminho da casa própria é sofrido. Tem que começar do chão, como dizia seu Jair, no meio do nada, sem apoio - o chão designa tanto a superfície do solo quanto uma área desprovida de melhoramento, como 
na expressão morar no chão, sinônima de morar numa rua sem asfalto. "Fui, comprei o terreno", me contou Jair, "aí que fomos construir isso aqui que eu vim do chão. Não tinha sábado nem domingo, só... e buracão aqui, depois de repente fomos conquistar e morando".

Tem que lutar para levantar uma casa do chão. Dona Clara insistia muito no valor do capricho, chamando de "rapaz muito caprichoso" e "trabalhador" o genro dela, que mora no andar de cima com a filha e os três netos dela. Isso porque não hesitava em gastar tempo e dinheiro nas obras (começou a construir o andar de cima quando engravidou a filha de dona Clara, mesmo ainda menor de idade). Ao contrário, o caçula, solteiro, que está fazendo a casa dele nos fundos, "é um pouco assim... farrista (rindo)!". Ou seja, não tem "ânimo", prefere gastar dinheiro na balada. Por isso, a obra dele "tá lá, parada".

Sacrifício é outra categoria acionada pelos moradores para falar das dificuldades do cotidiano, decorrentes das obras ou da falta de infraestrutura. "E quando chovia?", me contava dona Joaquina, "Que aquele barco, que era barco, tudo barco, ninguém podia nem passar, enterrava até os joelhos de lama. Pessoal que tinha que trabalhar lá pra fora, pegar a condução lá longe lá pra fora. Era um sacrifício, era muito sacrificado. Mas depois, graças a Deus melhorou tudo". "Era um sacrifício pra gente ir pro trabalho!", reclamava Lúcio, “Tinha que enfiar os pés dentro do saco de mercado pra poder passar!"

O pobre, em geral, vive uma vida de sofrimento, palavra que se aplica sintomaticamente à experiência da falta de urbanização - o sofrimento da água vira sinônimo de falta de água. Conforme sugerem palavras como lutar e sacrifício, os moradores não depreciam o sofrimento que acompanha a construção da casa ou precede a chegada do progresso, pelo contrário: o sofrimento é que dá valor ao progresso.

Arnaldo: A gente sofre um pouquinho de um lado, sofre do outro que... nada como... que você tem objetivo é sofrimento. Moleza você não dá valor em nada, você não vai no sofrimento, você nunca vai dar valor. Ganhar fácil... mas nem tudo é fácil. E aí, moro aqui cara, todo mundo tá aí, tem muito sofredor aí, muita gente comprou muita casa aí. Tem muita gente que sofreu muito. Sofreu muito, muito, muito mesmo.

Isso não quer dizer que a vida seja feita apenas de sacrifícios, mas que esses fazem sempre parte da vida. Bernard atrasou as obras da casa, devido a um problema na coluna, que o impede de exercer a profissão de pintor. Porém, ainda não conseguiu "dar entrada no INSS", para receber a pensão por invalidez. Mas isso faz parte da vida. "Isso aí às vezes a vida, a situação dos maus tempos né (rindo). Porque a gente sempre tem altos e baixos, a gente às vezes tem uma situação, daqui a pouco perde um pouquinho né. É a vida nossa aqui. Nossa vida aqui é assim". Ao ritmo das obras e do progresso contrapõe-se a sucessão dos sacrifícios; ao movimento ascendente, lento e atônico das melhorias, a repetição do sofrimento. 


\section{CONCLUSÃO: AGENCIAMENTO E LINHA DE FUGA}

Nossa hipótese inicial sugeria que, em meio à autoconstrução e às carências urbanísticas, existe certo modo de relacionar pessoas, casas e ruas, certa configuração de corpos, afetos e discursos, certo agenciamento. Trata-se de um agenciamento territorial: a partir da casa, as pessoas desenvolvem uma relação pragmática com a rua, com o mundo circundante, voltada para a realização de tarefas cotidianas, como beber água, transitar, fazer compras etc. Aqui é a circunspeção que junta os corpos e produz afetos - um mundo que pouco oferece para a realização dessas tarefas implica um mundo vazio e de sofrimento. A urbanização, o progresso, introduz o tempo nesse agenciamento territorial, separando o lugar atrasado (parado) do lugar evoluído. Esse lugar evoluído é um lugar em movimento, de transformações vividas como positivas - melhorar e valorizar - que refletem a percepção que os moradores têm de si no tempo melhorar de vida. É também um lugar de movimento, um lugar que se enche de pessoas, casas e comércios. Assim, o agenciamento territorial entrelaça várias formas de mobilidade: o progresso movimenta coisas e pessoas, sendo que esse movimento alimenta o sentimento de mobilidade existencial (melhorar de vida) e impõe um ritmo afetivo (aos poucos) à vida.

À semelhança do bairro ou da rua, o agenciamento que une a casa e a pessoa também está atravessado pelo desejo de melhorar de vida. As transformações da casa, reformas e expansões influem na autoimagem da pessoa, no sentimento de evoluir na vida. De modo geral, o processo da construção configura certa percepção do tempo: uma obra parada implica uma vida parada. Entre a casa e a pessoa, existe toda uma dinâmica socioafetiva, capturada pela expressão aos poucos: a construção da casa, assim como a urbanização, impõe um ritmo aos corpos, certa maneira de sentir o mundo, feita de melhoria, mas também de sofrimento, de um sofrimento necessário e repetitivo.

Uma utilização rigorosa do conceito deleuzo-guattariano de agenciamento permite, portanto, ampliar nossa compreensão das forças que juntam e movimentam pessoas e objetos, para além da "relacionalidade" ou da mera constatação de que as nossas vidas são compostas por entidades ontologicamente heterogêneas. Ela também abre caminho para uma comparação analiticamente mais densa. O caso da Bósnia, descrito por Jansen (2014), mostra que o sentimento de ficar parado na vida remete lá à percepção de uma movimentação política inadequada: com o fim do comunismo e o início da Guerra Civil Iugoslava nos anos I990, os bósnios consideram que perderam a segurança de ter uma "vida normal" - proteção social, férias no litoral, passaporte iugoslavo etc. No caso da Bósnia, contudo, também a percepção da mobilidade existencial está ancorada em certas materialidades. Apartamentos coletivos, fábricas, escolas e ferrovias funcionam, para os bósnios, como indícios dessa vida normal perdida, ao mesmo tempo em que o trabalho coletivo dos quais são o produto lembra a antiga ordem política: todo um agenciamento, um emaranhado de desejos, discursos e materialidades. 
Quero ressaltar que a vida dos moradores do Jardim Maravilha não se resume ao agenciamento territorial descrito, que, ao lado do desejo de melhorar de vida, existem outros desejos e outros agenciamentos - como o da política, apenas sugerido aqui na percepção nativa da lama. E conforme a intuição fundamental de Deleuze e Guattari, esses agenciamentos alternativos muitas vezes surgem nos disfuncionamentos dos outros, nas suas "linhas de fuga". Crescer, por exemplo, pode significar algo positivo, mas também ameaçador: um lugar que cresce corre o risco de perder sua tranquilidade, de se tornar vítima da violência, de não ter mais contato com a natureza; um lugar onde as pessoas não se conhecem mais, onde os problemas causados pela urbanização (o aumento do trânsito automóvel, por exemplo) se multiplicam. Essas "linhas de fuga" revelam o quão complexa é a experiência histórica das classes populares morando na periferia de uma cidade como o Rio de Janeiro, e acredito que essa é mais uma perspectiva aberta pelo conceito de agenciamento.

Recebido em I 2/o9/20I9 | Revisto em I8/I I/20I9 | Aprovado em I9/I I/20I9

Thomas Jacques Cortado é doutor em antropologia social pelo Museu Nacional (PPGAS/MN/UFRJ) e ex-aluno da Escola Normal Superior de Paris (ENS-Ulm). Atualmente faz pós-doutorado na Universidade Estadual de Campinas (Unicamp) com bolsa Fapesp. Integra o Núcleo de Estudos sobre Cultura e Economia (Nucec) e o Grupo Casa. Estuda processos de urbanização nos limites das grandes metrópoles, por meio das interações entre práticas de autoconstrução, dinâmicas familiares, relações de propriedade e tecnologias de governo nos loteamentos periféricos do Rio de Janeiro. 


\section{NOTAS}

I Este artigo apresenta o material etnográfico coletado no Jardim Maravilha entre 20I4 e 2016 (Cortado, 202I). Além de inúmeras observações e conversas informais, gravei aproximadamente 40 entrevistas semiestruturadas nesse período.

2 Os termos do vocabulário nativo aparecem entre aspas em sua primeira menção.

3 Preferi a palavra de origem francesa bricolagem a gambiarra uma vez que esta última tem conotação de improviso, inexistente na primeira. Em vez de improviso, a bricolagem infraestrutural na periferia me parece apontar para uma alta organização da ação coletiva, capaz de gerar soluções duráveis para problemas estruturais.

4 Entre as várias traduções possíveis para o termo alemão Umwelt, muitas vezes sinônimo de meio ambiente, escolhi mundo circundante, da tradutora Marcia Sá Cavalcante Schuback, pois mantém o significado do prefixo um- que, em alemão, remete à noção de entorno. O vocábulo Umwelt tem nítida conotação espacial, central na elaboração de Heidegger e para o meu argumento, que a tradução de Schuback consegue capturar. Já a expressão mundo próprio remete apenas à dimensão doméstica do mundo circundante, que também possui uma dimensão pública: o Mitwelt (Heidegger, 2005: I05), mundo compartilhado.

5 Agradecendo a sugestão de um revisor, gostaria de esclarecer aqui a distinção entre agenciamento e mundo circundante, propondo uma breve genealogia de ambos. O conceito deleuzo-guattariano de agenciamento deriva em parte do de mundo circundante ao qual o biólogo Jacob von Uexküll recorreu para escapar da alternativa entre mecanismo e vitalismo na explicação dos comportamentos animais: o exemplo do carrapato, sempre citados por Deleuze e Guattari (1997: 36) para ilustrar o conceito de agenciamento, vem do biólogo estoniano. Entretanto, os dois filósofos franceses reinterpretaram von Uexküll no contexto de uma crítica à psicanálise e ao estruturalismo, que atribuem a movimentação dos corpos (o desejo) a causas externas (o triângulo edipiano ou as regras universais do inconsciente). A palavra agenciamento, pela sua proximidade com o 
verbo agenciar, tem a vantagem de resgatar a criatividade do desejo. Já o Heidegger de Ser e tempo tem como ponto de partida não o desejo, mas as condições de aparição do mundo, na pura tradição da fenomenologia. A circumundanidade seria a nossa maneira original de ir ao encontro do mundo, marcada pela manualidade (ou disponibilidade). Escolhi tratar a circumundanidade como caso particular de agenciamento, pautado na manualidade, visto que existem outras possibilidades de agenciar relações. Vale ressaltar que, para todos os autores citados, está em jogo o diálogo entre a percepção e a ação: é justamente esse diálogo que eu quero recuperar aqui, em contraposição ao conceito contemporâneo de assemblage.

6 Em um belo artigo sobre a mobilidade dos trabalhadores de grandes projetos modernizantes (tipo barragem hidráulica), no norte de Goiás, Guedes (2013b: 329) ressaltou a ênfase que eles dão ao que "há de agressivo na exposição ao clima”, como a chuva, a lama, o sol e a poeira. À hostilidade dos ambientes se opõe a "familiaridade do lar ou da terra de origem" (Guedes, 2013b: 326).

7 Contando a vida das cidades no norte de Goiás, Guedes (2015: I22) opôs a "cidade movimentada ou animada, com suas ruas abarrotadas, o dinheiro correndo, idas e vindas de gente de todo canto, confusão, malandragem, morte e festa se misturando" à "cidade parada", que não oferece mais perspectiva de "evolução" para as pessoas. Contudo, enquanto no caso analisado por Guedes, o movimento vem das febres trazidas pela atividade econômica (mineração, construção de barragem), aqui o movimento surge com as obras de urbanização.

8 Facilita o planejamento da casa a reserva de espaço à disposição de quem compra um terreno novo: no Jardim Maravilha, os lotes possuem, em geral, $225 \mathrm{~m}^{2}$, tamanho-padrão dos "lotes proletários" (Cortado, 202I). Acredito haver aqui uma importante diferença com as favelas, onde a escassez de espaço disponível constrange as possibilidades construtivas. 


\section{REFERÊNCIAS BIBLIOGRÁFICAS}

Cavalcanti, Mariana. (2007). Of shacks, houses and fortresses. Tese de Doutorado. Departamento de Antropologia/Universidade de Chicago.

Comerford, John. (2014). Vigiar e narrar: sobre formas de observação, narração e julgamento de movimentações. Revista de Antropologia, 57/2, p. I07-I42.

Cortado, Thomas Jacques. (no prelo). À beira da cidade: política e poética do loteamento. Rio de Janeiro: 7Letras.

Cortado, Thomas Jacques. (2019). Meia-água: producing space and kinship in an irregular housing subdivision in Rio de Janeiro. Journal of Urban Research [online], 20. Disponível em <https://journals.openedition.org/articulo/ 4355>. Acesso em 30 mar. 202 I.

Deleuze, Gilles \& Guattari, Félix. (1997). Mil platôs. São Paulo: Editora 34 .

Deleuze, Gilles \& Parnet, Claire. (I998). Diálogos. São Paulo: Escuta.

Durham, Eunice R. (1989). A sociedade vista da periferia. Revista Brasileira de Ciências Sociais, I/I, p. 84-99. Disponível em http://anpocs.com/images/stories/RBCS/oI/rbcsoI_07. pdf. Acesso em 2 abr. 202 I.

Guedes, André Dumans. (2017). Construindo e estabilizando cidades, casas e pessoas. Mana, 3/3, p. 403-435.

Guedes, André Dumans. (20I5). Andança, agitação, luta, autonomia, evolução: sentidos do movimento e da mobilidade. Ruris, 9/I, p. III-I4I.

Guedes, André Dumans. (2013a). Fever, movements, passions and dead cities in Northern Goiás. Vibrant, II/I, p. 56-95.

Guedes, André Dumans. (2013b). Na estrada e na lama com Jorge, um brasileiro. Trabalho e moradia nas fronteiras do desenvolvimento. Horizontes Antropológicos, I9/39, p. 19-345. Hage, Ghassan. (2009). Waiting out the crisis: on stuckedness and governmentality. In: Hage, Ghassan (org.). Waiting. Victoria: Melbourne University Press, p. 97-Io6.

Hage, Ghassan. (2005). A not so multi-sited ethnography of a not so imagined community. Anthropological Theory, 5/4, p. 463-475. 
Handerson, Joseph. (2012). Diaspora. Sentidos sociais e mobilidades haitianas. Horizontes Antropológicos, 2I/43, p. 5I-78.

Heidegger, Martin. (2005). Ser e tempo. Petrópolis: Vozes. Jansen, Stef. (20I4). On not moving well enough: temporal reasoning in Sarajevo yearnings for "normal lives". Current Anthropology, 55/S9, p. S74-S84.

Lévi-Strauss, Claude. (1960). La pensée sauvage. Paris: Plon. Lopes, José Sérgio Leite. (I979). Fábrica e vila operária: considerações sobre uma forma de servidão burguesa. In: Lopes, José Sérgio Leite et al. (orgs.). Mudança social no Nordeste. Rio de Janeiro: Paz e Terra, p. 4I-98.

Marcelin, Louis Herns. (1996). L'invention de la famille afro-américaine: famille, parenté et domesticité parmi les noirs du Recôncavo da Bahia. Tese de Doutorado. PPGAS/Universidade Federal do Rio de Janeiro.

Maricato, Ermínia (org.). (I979). A produção capitalista da casa (e da cidade) no Brasil industrial. São Paulo: Alfa-Omega. Mitchell, Timothy. (I99I). Colonising Egypt. Berkeley/Los Angeles/London: University of California Press.

Oliveira, João Pacheco de. (I998). Uma etnologia dos "índios misturados"? Situação colonial, territorialização e fluxos culturais. Mana, 4/I, p. 47-77.

Rabinow, Paul. (1995). French modern. Chicago/London: The University of Chicago Press.

Santos, Carlos Nelson Ferreira de. (I980). Velhas novidades nos modos de urbanização brasileiros. In: Valladares, Lícia do Prado (org.). Habitação em questão. Rio de Janeiro: Zahar, p. I7-48.

Vaysse, Jean-Marie. (2007). Dictionnaire Heidegger. Paris: Ellipses.

Von Uexküll, Jacob. (1965). Mondes animaux et monde humain. Paris: Denoël.

Wagner, Roy. (I99I). Big men and great men: personifications of power in Melanesia. Cambridge/New York/Paris: Cambridge University Press/Éditions de la Maison des Sciences de l'Homme, p. I59-I73. 


\section{Palavras-chave \\ Periferia; agenciamento; urbanização; autoconstrução; mobilidade.}

Keywords Urban periphery; assemblage; urbanization; self-construction; mobility.

\section{AOS POUCOS: AGENCIANDO PESSOAS, CASAS E RUAS NA PERIFERIA DO RIO DE JANEIRO}

Resumo

Com base no estudo etnográfico do Jardim Maravilha, loteamento periférico do Rio de Janeiro, o artigo alveja dois objetivos: entender o lugar da casa no modo como os moradores da periferia se apropriam do tempo e do espaço; e revelar o potencial heurístico do conceito de agenciamento (Deleuze \& Guattari). Discute inicialmente os conceitos de mobilidade, mostrando como o confronto entre eles e as práticas da casa levam à formulação de um novo: a mobilidade intensiva. Em seguida, trata de urbanização e autoconstrução sob o ângulo das práticas (bricolagem infraestrutural) e dos discursos nativos (progresso), os quais apontam para uma apropriação pragmática do mundo (agenciamento territorial), mas também "intensa": a expressão "aos poucos", em particular, indica uma vida vivida de forma lenta, regular e discreta, por contiguidade - aos poucos, amplia-se a casa, asfalta-se mais uma rua. Conclui com os desdobramentos analíticos da abordagem proposta.

\section{LITTLE BY LITTLE: ASSEMBLING PERSONHOODS, HOUSES AND STREETS IN THE RIO DE JANEIRO PERIPHERY}

\section{Abstract}

Based on an ethnographic fieldwork in Jardim Maravilha, a peripheral subdivision located in Rio de Janeiro, the article aims at two objectives: to understand how the people living in the urban peripheries appropriate time and space through the house; to reveal the heuristic potential of the concept of assemblage (Deleuze \& Guattari). First, it discusses the concepts of mobility, showing how the confrontation between those and housing practices leads to the formulation of a new one: intensive mobility. Then, it deals with urbanization and self-construction through native practices (infrastructural bricolage) and ideas (progress). These practices and ideas point to a pragmatic appropriation of the world (territorial assemblage), which is also an intense one: the popular expression "little by little", in particular, indicates a life lived slowly, regularly and unnoticeably, by contiguity - little by little, the house expands, another street starts to benefit from public services. The article concludes on further analytical developments. 